\title{
HUMAN RESOURCING CHALLENGES OF THE SMART GRIDS DEPLOYMENT PROJECTS IN RUSSIA
}

\author{
Alexander Y. Chmykhalo, ${ }^{1, *}$, Vasilya R. Khaliulina ${ }^{1}$, and Olga V. Mikhailova ${ }^{1}$ \\ ${ }^{1}$ Tomsk Polytechnic University, 634050, Tomsk, Russia
}

\begin{abstract}
The article addresses the issue of the causes of human resources gaps for the implementation of projects for the deployment of intelligent electricity grids. The "focus group" research technique used in Tomsk Polytechnic University enabled to identify numerous barriers encountered by present-day engineering students in Russia on the path of their professional development. The barriers explored impede greatly the creation and introduction of state-of-the-art technological systems, Smart Grid being one of them. The elimination of those barriers will accelerate the accomplishment of the Smart Grid project.
\end{abstract}

\section{Introduction}

The current socio-economic situation in the world is characterized by intense competition in the field of innovations development among the countries. The governments of many countries are taking extra measures to engage the population in entrepreneurial activities and innovation development.

Many scientific papers tend to present the process of promoting innovation development as a complex problem, requiring an integrated approach for its analysis, according to which creativity, innovation and entrepreneurship make up an integrated entity, or "construct". That construct is viewed not only as an engine driving forward a country's socio-economic development, but also as a meta-competence to be addressed in the education system, particularly in the system of engineering education $[1,2]$. How to integrate approaches aimed at training enterprising, creative-minded, innovation-oriented graduates into existing universities' curricula is at the core of the current education agendas in all the world's countries that face the urgency of social and technological modifications of their academic institutions for the purpose of their upgrading. Increasingly topical is this issue for the system of engineering education designed to simultaneously maintain advanced scientific and technical research and encourage the development of novel products and technologies to meet societal needs and priorities $[3,4]$. Universities are becoming increasingly aware of the need to graduate engineers with a creative mindset, capable of designing new products and services, equipped with methods of recognizing market trends, detecting people's needs as well as evaluating social challenges [5].

\footnotetext{
*Corresponding author: ovmtom@tpu.ru
} 
Under these conditions, there is a growing concern in many countries about the quality of engineering education. It has been reported that fewer young men choose science and engineering careers despite the increased labour market demand for experienced engineers and technicians since new technical systems have more and more application opportunities and require more "active feedback" from end-users [6]. The deployment and maintenance of those systems necessitate collaborative working, which, in its turn, requires a new set of professionals and engineers with augmented competences.

The most striking example of those novel technical systems launched in the world's developed countries over the past decades is the intelligent power supply system - Smart Grid. Among the problems that the European Union countries have faced while implementing the program for Smart Grids deployment the most crucial one has turned out to be that of human resourcing. The "European Technology Platform Smart Grids. Strategic Deployment Document for Europe's Electricity Networks of the Future" published in 2010 highlights that "engineering in the energy sector, electricity grids in particular, is seen by many as old-fashioned and "difficult" as it requires a high level of competence in mathematics, physics and other sciences. This discourages the potential new students from studying and pursuing a career in power engineering" [7].

In response to this claim, the aim of this study is to find out whether the idea of power engineering being 'old-fashioned and difficult' is shared by Russian students in the Tomsk Polytechnic University (TPU) (one of the leading institutions of engineering education in Russia) [8]. What are the students' perceptions of the skills and competences the presentday engineer should possess? What, they believe, are the greatest barriers hampering the professional development of the engineer?

The challenge of providing the engineering personnel for the implementation of Smart Grids programs in Russia, in the city of Tomsk in particular, is of special importance to us, because, it was in Tomsk where the development of intellectual power systems in Russia was started. In 2011, the "Intellectual Power Supply Systems" research center was established to produce high-technology methods for heating, power supply and telecommunication. However, thus far, there has not been any noticeable breakthrough in these fields either on the territory of the Tomsk region, or any other region of Russia. The analysis of the current situation makes us suggest that one of the key barriers constraining the implementation of that, as well as other innovative projects, is human resourcing, namely the shortage of engineering graduates whose professional skills and competences are enough to adequately respond to the challenges of an innovation-driven economy [9].

The purpose of this paper is by using the "focus group" research technique to examine the perception held by Russian students of the content of an engineering major, of the most significant barriers impeding the professional engineering training in Russia.

The sampling frame for the study consisted of students enrolled in a Bachelor's degree programme in "Electrical engineering and equipment" and in a Master's degree programme in "Nuclear physics and nuclear energy technology at the Institute of Physics and Technology and the Institute of Power Engineering in TPU'. The survey and its analysis were implemented in 2016.

\section{Results and discussion}

For the purpose of the survey two sets of questions were offered to respondents. The first set questions were designed to explore the contemporary Russian students' perception on the content of an engineering major, the distinctive attributes and abilities of engineers in comparison with other specialists. A second set of questions was aimed at detecting the main barriers having negative implications for the professional development of the presentday engineer. The survey enabled the respondents to convey their position on the issues 
under study. The list of essential qualitative characteristics given below represents the views shared by the majority of respondents:

1. The main objective of the professional activity of the engineer is to invent, design and produce new equipment, to devise and develop new materials and products.

2. The present-day engineer has to have good professional education. An engineering graduate has to be provided with a profound grounding in engineering disciplines, to have scientific research experience, to keep track of the latest science and technology advancements.

3. The engineer has to be able to use information technology and related applications to convey and retrieve information, to use presentation software to create, edit, and give digital representations of information about produced items, and deliver oral selfpresentations.

4. The present-day engineer has to be able to use available and create new channels of retrieving information, to work cooperatively with others, as either a leader or a follower, on the project, participate in professional or other social groups and communities both nationally and internationally.

5. The present-day engineer aspires to be the best in his field and demonstrates a commitment to self-development and improvement of knowledge and expertise by self-education and by participating in relevant training and professional development programs.

6. The well-qualified engineer has to possess and use knowledge pertinent not only to the specific area of engineering practice or allied sciences, but also Humanities, Social Sciences, Economics.

7. Engineers are people who solve problems of others by means of technical devices. Engineers are capable of coming up with fresh, original, but workable ideas to address some routine problems.

The analysis of the results of the survey has made it possible to identify a few main barriers affecting various aspects of the present-day engineering training:

1) firstly, there are barriers connected with the content of engineering education in Russian universities:

- the shortage of academic hours in engineering major subjects at a bachelor's degree level;

- a big share of the engineering departments syllabi is taken up by humanitarian and socio-economic courses whose content does not always correlate with the major subjects courses and does not contribute to the formation of the requisite knowledge and skills in management and communication;

- the constant growth of information to be processed and absorbed makes it imperative to apply an integrated interdisciplinary approach to curriculum development.

2) secondly, there are barriers connected with the organization and supervision of learning and research processes of engineering students:

- with a student having just one research supervisor, there are risks of their adopting not only positive attributes of the latter, but also negative ones. There is a need for students' being involved in diverse scientific societies and communities at the department, university and inter-university levels. The sharing of scientific information within those communities has to be ensured.

- good engineers can be prepared only by good engineers. There is a lack of, though a great demand for effective highly-qualified university teachers;

- a poor level of the organization of students professional practice at enterprises, which looks more like an orientation field-trip. Employers are not motivated to offer really challenging workplacement experiences, as a consequence, graduates 
don't get a real insight into the modern enterprise and find themselves neglected by employers;

- rarely do industry's leading enterprises offer work experience opportunities, so there is no chance for students to familiarize with their best practices;

- students have low motivation for research and inventions development, as those activities do not affect directly their employment and traineeship opportunities;

3) thirdly, there are barriers connected with the shortcomings of the country's educational system in general:

- the level of school education is stated to have declined, which entails having fewer young people aspiring to engineering training;

- there is no logical and content continuity between the programs of baccalaureate and Master's degree levels;

- there is no explicit strategy for the development of engineering industries and engineering education in the country, as a result, there is a great number of misguided school-leavers making future career decisions;

4) fourthly, there are cultural and value barriers:

- the notably lower social and economic status of the engineer in the modern society (a low prestige of a profession with the population);

- the public is reluctant to accept changes initiated by engineers, so there is no due concern in the society about involving young people in engineering, which discourages them from pursuing engineering careers;

- the society doesn't have a clear idea of the role of young specialists (engineers) in its economic, political and social life, lacks explicit value imperatives with regard to young people;

- with the government participating greatly in the national economy, political feasibility is a crucial guiding force for the state bureaucracy in decision-making, thus innovations are being neglected;

The analysis of our survey results makes it possible for us to argue that they correlate in many aspects with other findings addressing the quality of engineering education in Russia, and in TPU in particular. Those findings cover the statistical data on the employment of Bachelor's programs graduates, the number of innovative enterprises launched by TPU graduates, income earned from vending invention patents granted to TPU students, lecturers, engineers [8], etc.

\section{Conclusion}

The data analysis of the deployment plans for electricity networks of the future (Smart Grids) in the European Union countries clearly demonstrates that providing human resources (engineers, technicians and craft personnel) for the project is a crucial factor in its successful completion. The results of the survey conducted among TPU students acknowledge the topicality of the human resourcing challenge in Russia. The numerous barriers impeding the process of training competent, creative, innovation-minded engineers have been identified. The impact of those barriers is tangible even in the universities regarded as the clear leaders of power engineering education in Russia.

Thus, we can argue that human resourcing is a major obstacle to the implementation of the smart grids deployment project in the Tomsk region, and Russia as a whole. For the future intelligent electricity grids to be introduced it is urgent to undertake efforts and activities to eliminate the identified and explored barriers. 
This work was carried out with the financial support from the grant of the Russian Humanitarian Science Foundation (RHSF) (project No. 16-16-70006).

\section{References}

1. M. Edwards-Schachter, A. García-Granero, M. Sánchez-Barrioluengoa, H. QuesadaPineda, N. Amara, Thinking Skills and Creativity 16, 27 (2015)

2. B. Ardashkin, L. A. Korobeynikova, A. V. Popova, Status of social competencies of power engineers in the context of forming the concept of an intelligent network or smart grid, MATEC Web of Conf. 37, 01003 (2015)

3. M. A. Makienko, N. V. Kurkan, A. A. Strelcowa, Philosophical approach to engineering education under the introduction of the smart grid concept in Russia, MATEC Web of Conf. 37, 01031 (2015)

4. D. K. Gattie, N. K. Kellam, J. R. Schramski, J. Walther, EJEE 36, 521 (2011)

5. M. H. Morris, J. W. Webb, J. Fu, S. Singhal, JSBM 51, 352 (2013)

6. R. Freeman, National Bureau of Economic Research, Working Paper 11457, (2005)

7. Smart Grids European Technology Platform. URL: http://www.smartgrids.eu/

8. A.Y. Chmykhalo, O. V. Mikhailova, N. A. Vtorushin, R. A. Bykov, Innovation development in Russia: the value aspect, SHS Web of Conf., 28 (2016)

9. A.Y. Chmykhalo, V. R. Khaliulina, M. E. Abushaeva, Innovative Power Systems and The Formation of The Creative Class in Russia, MATEC Web of Conf. 37, 01016 (2015) 